\title{
Campylobacter fetus subespécie fetus: abortamento e natimortalidade em ovinos
}

\author{
Campylobacter fetus subspecies fetus: abortion and stillbirths in sheep
}

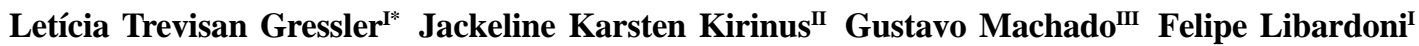 \\ Agueda Castagna de Vargas ${ }^{\mathrm{I}}$
}

\begin{abstract}
A bactéria do gênero Campylobacter está RESUMO A bactéria do gênero Campylobacter está
comumente envolvida em surtos de abortos ovinos em muitos países. No Brasil, até o presente momento, ainda não houve relato sobre a ocorrência de aborto em ovinos causado pelo $\boldsymbol{C}$. fetus, subespécie fetus (C. fetus ssp. fetus). No presente trabalho, relata-se a detecção deste agente em fetos e natimortos ovinos naturalmente infectados. Desse modo, alerta-se para a possibilidade de novos casos de aborto em ovinos causados por C. fetus ssp. fetus.
\end{abstract}

Palavras-chave: aborto, natimorto, Campylobacter fetus subesp. fetus, ovino, PCR.

\section{ABSTRACT}

The bacteria of genus Campylobacter spp, is commonly involved in outbreaks of ovine abortion in many countries. In Brazil, until now, there has been no report on the occurrence of abortion in sheep caused by $\mathrm{C}$. fetus subsp. fetus. In this paper, we report the detection this bacteria in ovine fetuses naturally infected. Thus, alert for possible cases of abortion in sheep caused by $\mathbf{C}$. fetus subsp. fetus.

Key words: abortion, Campylobacter fetus subesp. fetus, ovine, PCR.

Abortamento e natimortalidade em ovinos, embora frequentes, não são diagnosticados de maneira definitiva em cerca 56\% dos casos (KIRKBRIDE, 1993). Quando determinados, os principais agentes infecciosos envolvidos são: Toxoplasma gondii, Campylobacter fetus subespécie fetus (C. fetus ssp. fetus), Yersinia pseudotuberculosis, Fusobacterium necrophorum, Escherichia coli, Listeria monocytogenes, Brucella ovis, Campylobacter jejuni, Campylobacter coli, Chlamydophila abortus e Neospora caninum (KIRKBRIDE, 1993; WEST et al., 2006; ENTRICAN et al., 2010). Em um estudo com 1.784 produtos de abortamento e natimortalidade, observouse que T. gondii, C. abortus e Campylobacter spp., juntos, foram responsáveis por $25 \%$ dos casos (KIRKBRIDE, 1993).

No Brasil, da mesma forma, estes são os agentes mais comumente citados como prováveis causas de abortamento e natimortalidade em ovinos, no entanto, a maioria dos relatos está baseada em evidências sorológicas para $C$. abortus, $N$. caninum (HELMICK, et al., 2002) e T. gondii (PINHEIRO et al., 2009). Dessa forma, estudos demonstrando a etiologia são escassos, dentre eles, VARGAS et al. (2005) relataram o isolamento e identificação de $\boldsymbol{C}$.jejuni em um feto ovino abortado e MORAES et al. (2011), a detecção molecular de T. gondii em tecidos fetais.

'Laboratório de Bacteriologia da Universidade Federal de Santa Maria (UFSM), Av. Roraima, 1000, 97105-900, Santa Maria, RS, Brasil. E-mail: letrevi@gmail.com.*Autor para correspondência.

IINúcleo Integrado de Desenvolvimento em Análises Laboratoriais (NIDAL), UFSM, Santa Maria, RS, Brasil.

IIL Laboratório de Epidemiologia Veterinária (EPILAB), Setor de Medicina Veterinária Preventiva, Faculdade de Veterinária, Universidade Federal do Rio Grande do Sul (UFRGS), Porto Alegre, RS, Brasil. 
Diante disso, o presente trabalho tem por objetivo relatar, pela primeira vez no Brasil, o C. fetus ssp. fetus como etiologia em casos de natimortalidade e abortamento em ovinos naturalmente infectados.

O primeiro caso ocorreu em abril de 2005, no município São Vicente do Sul, localizado no Rio Grande do Sul (RS), onde ocorreram dois casos de natimortos em ovelhas de um rebanho de 150 matrizes da raça Ile France. Os animais estavam alocados em um sistema de semiconfinamento, eram alimentados com pastagem (aveia e milheto) e apresentavam boa condição corporal. Os natimortos possuíam 150 dias de idade e mediam $40 \mathrm{~cm}$ de comprimento, da nuca ao sacro. Foi a primeira vez que ocorreu este tipo de problema reprodutivo na propriedade.

Em maio de 2010, no município Dilermando de Aguiar, no RS, ocorreram quatro casos de aborto em ovelhas da raça Texel, no período de dois dias. O rebanho era composto por 800 animais, sendo 400 matrizes. Os animais viviam em semiconfinamento, eram alimentados com pastagem nativa e cultivada (aveia e azevém), e apresentavam boas condições físicas. Os fetos possuíam 105 dias de idade e mediam $30 \mathrm{~cm}$ de comprimento, da nuca ao sacro. Nessa propriedade, no ano de 2009, ocorreram casos de aborto, sem diagnóstico conclusivo.

Nos casos aqui apresentados, os proprietários relataram natimortalidade e abortamento no terço final da gestação em duas e quatro ovelhas da raça Ile France e Texel, respectivamente. Os animais eram vacinados contra carbúnculo sintomático, enterotoxemia e leptospirose. Além disso, eram vermifugados regularmente, a cada 60 dias, e submetidos ao pastoreio rotativo em diferentes piquetes. Em ambos os casos, não houve relato de alteração no manejo dos ovinos que possa estar relacionada aos problemas reprodutivos apresentados acima. Além dos ovinos, caninos, felinos, aves e equinos tinham acesso aos mesmos ambientes. Após uma longa anamnese, suspeitou-se de campilobacteriose.

Os produtos de abortamento e natimortalidade foram submetidos à necropsia no Laboratório de Patologia Veterinária até 12 horas após a morte. Durante a necropsia, foram coletados órgãos (pulmão, fígado, coração, rim, adrenal, abomaso, intestino delgado e grosso, reto e encéfalo) para exames histopatológicos e bacteriológicos.

Amostras de fígado e líquido abomasal foram semeadas em base de ágar $\left(\right.$ Oxoid $\left.^{\circledR}\right)$ acrescido de $10 \%$ de sangue ovino e incubadas a $37^{\circ} \mathrm{C}$ por 72 horas em aerobiose e microaerofilia $\left(10 \% \mathrm{CO}_{2}, 6 \% \mathrm{O}_{2}, 84 \%\right.$ $\mathrm{N}_{2}$ ). Além disso, as amostras foram também incubadas a $37^{\circ} \mathrm{C}$ por três dias em meio de transporte e enriquecimento (TEM) (LANDER, 1990) e após foram semeadas em base de ágar $\left(\mathrm{Oxoid}^{\circledR}\right)$ acrescido de $10 \%$ de sangue ovino e incubadas a $37^{\circ} \mathrm{C}$ por 48 horas em microaerofilia. Em seguida, realizou-se análise morfológica, tintorial e bioquímica das culturas, segundo QUINN et al. (2005).

A caracterização molecular foi realizada em amostras oriundas do meio TEM após cinco dias de incubação, através da extração de DNA pelo protocolo de CTAB (brometo de cetil trimetil amonio), precedido por uma digestão com $5 \mu \mathrm{L}$ de proteinase $\mathrm{K}(20 \mathrm{mg} / \mathrm{mL})$ por 60 minutos a $37^{\circ} \mathrm{C}$ (SAMBROOK \& RUSSELL, 2001) e, posteriormente, submetido à técnica da reação da polimerase em cadeia (PCR). Para identificação molecular do gênero e espécie de Campylobacter, foram utilizados os primers (Fet1F 5, CTCATAATTTAATT GCACTCATA 3' e 69Rar 5', CTTAGGACCGTTATAGTTAC 3') (BASTYNS et al.,1994). Já para caracterizar as subespécies de C. fetus, foram utilizados dois pares de primers (MG3F 5, GGTAGCCGCAGCTGCTAAGAT 3' e MG4R 5' TAGCTA CAATAACGACAACT 3' e VENSF1 5' CTTAGCAGTTTGCGATATTGCCATT e VENS 2 5'GCTTTTGAGATAACAATAAGAGCTT 3') (HUM et al., 1997). A mistura para reação constou de $5 \mu \mathrm{L}$ de DNA molde, adicionados ao mix do PCR, contendo: $25 \mathrm{pmol}$ de cada primer, $10 \mathrm{mM}$ de Tris- $\mathrm{HCl}, 50 \mathrm{mM}$ de $\mathrm{KCl}, 2 \mathrm{mM}$ de $\mathrm{MgCl}_{2}, 200 \mu \mathrm{M}$ de cada oligonucleotídeos (dNTPs) e 1U Taq DNA polimerase. Os resultados da PCR foram verificados em gel de $1,5 \%$ de agarose, corados com brometo de etídio e visualizados sob luz ultravioleta. Como controle, foi utilizado o DNA extraído das cepas de referência de $\boldsymbol{C}$. fetus ssp. fetus (ATCC 27374) e C. fetus ssp. venerealis (ATCC 19438).

A necropsia não revelou alterações macroscópicas significativas, apenas alterações autolíticas. Nos fígados, foi observada congestão difusa moderada a acentuada e consistência reduzida, o que não sugere o diagnóstico relacionado à suspeita inicial, uma vez que as lesões patognomônicas para campilobacteriose são necróticas circulares de $2 \mathrm{~cm}$ de diâmetros com bordas elevadas, claras e centros deprimidos e escuros na superfície do fígado de cordeiros abortados (QUINN et al. 2005). Ao exame histopatológico, observou-se congestão e hemorragia multifocal a coalescente acentuada no timo, autólise difusa moderada no intestino delgado, autólise difusa acentuada, com hemorragia multifocal leve nos rins e congestão difusa acentuada no encéfalo.

$\mathrm{Na}$ análise microbiológica, não foi evidenciado crescimento bacteriano compatível com Campylobacter spp., E. coli, L. monocytogenes, B. 
abortus e $Y$. pseudotuberculosis. No entanto, na caracterização molecular, de acordo com BASTYNS et al. (1994), foi verificada uma amplificação de 835 pares de base (pb), identificando-o como C. fetus. $\mathrm{Na}$ sequencia, a fim de determinar a subespécie, utilizaramse dois pares de primers, sendo visualizado somente um produto de $750 \mathrm{pb}$, identificando as amostras de DNA extraído como $\boldsymbol{C}$. fetus ssp. fetus, de acordo com WAGENAAR et al. (2001).

Diante do achado, recomendou-se aos proprietários o isolamento dos animais envolvidos nos casos, a fim de prevenir novas infecções, uma vez que esses podem apresentar a colonização da vesícula biliar após a infecção, eliminando de forma intermitente o $\mathbf{C}$. fetus ssp. fetus (HIRSH, 2003). No entanto, segundo QUINN et al. (2005), C. fetus ssp. fetus, bem como C. jejuni e $\boldsymbol{C}$. coli, podem estar presentes no trato intestinal de ovinos, podendo causar abortos esporádicos.

As bactérias do gênero Campylobacter são estritamente microaerófilas, logo, não persistem na atmosfera rica em oxigênio e não são encontradas no meio ambiente, além de apresentarem crescimento fastidioso em meios de cultura artificiais (QUINN et al., 2005) e necessitarem de condições especiais de transporte (HUM et al., 1997). Essas características, aliadas ao grau de autólise verificado durante o exame histopatológico, podem justificar a ausência de isolamento do $\boldsymbol{C}$. fetus ssp. fetus.

No Rio Grande do Sul, estima-se 15\% a 40\% de mortalidade em cordeiros (LOBO, 2002). A principal causa é o complexo inanição/hipotermia, responsável por $56 \%$ a $78 \%$ das mortes, seguido das distocias $(8,6 \%$ a 16,7\%) (HANCOCK et al., 1996). A predação primária, as infecções neonatais, os abortos, natimortos e as malformações congênitas são pouco frequentes, com menos de $5 \%$ para cada uma delas (NÓBREGA et al., 2005).

A identificação do agente etiológico pela detecção do seu DNA, em comparação ao método bacteriológico, torna a PCR uma alternativa prática aos laboratórios de diagnóstico. Essa técnica elimina a necessidade de isolamento e testes bioquímicos em micro-organismos de crescimento fastidioso e com poucas características bioquímicas para identificação, como é o caso de bactérias do gênero Campylobacter (HUM et al., 1997).

O resultado da análise molecular confirmou a suspeita inicial, sendo detectado o $\boldsymbol{C}$. fetus ssp. fetus. Por se tratar do primeiro relato no Brasil, alertamos para o diagnóstico molecular associado ao fenotípico, a fim de aumentar a sensibilidade em busca de se determinar a etiologia, bem como estabelecer o controle adequado da doença no rebanho.

\section{REFERÊNCIAS}

BASTYNS, K. et al. Species-specific detection of Campylobacters important in veterinary medicine by PCR amplification of 23rDNA areas. Systems Applied Microbiology, v.17, p.563-568, 1994. Disponível em: <http:/ /www.sciencedirect.com/science/articl2011800779>. Acesso em: 15 nov. 2010. doi:. 10.1016/S0723-2020(11)80077-9.

ENTRICAN, G. et al. Chlamydial infection in sheep: immune control versus fetal pathology. Journal of the Royal Society of Medicine, v.94, p.103-108, 2010. Disponível em: <http:/ /www.ncbi.nlm.nih.gov/pmc/articles/PMC1281521/>. Acesso em: 20 nov. 2011

HANCOCK, R.D. et al. Perinatal mortality in lambs in southern Brazil. Tropical Animal Health and Production, v.28, p.266-272, 1996. Disponível em: <http:// www.springerlink.com/content/73488582jr383041>. Acesso em: 12 nov. 2010 . doi: 10.1007/BF02240815.

HELMICK, B. et al. Serological investigation of aborted sheep and pigs for infection by Neospora caninum. Research in Veterinary Science, v.73, p.187-189, 2002. Disponível em: $<$ http://www.sciencedirect.com/science/article/pii/ S0034528802000930>. Acesso em: 20 nov.2011. doi:. 10.1016/S0034-5288(02)00093-0.

HIRSH, D.C. Campylobacter - Arcobacter (Sistema reprodutivo). In: HIRSH, D.C.; ZEE, Y.C. Microbiologia veterinária. Rio de Janeiro: Guanabara, 2003. Cap.36, p.181184.

HUM, S. et al. Evaluation of a PCR assay for identification and differentiation of Campylobacter fetus subsp. Australian Veterinary Journal, v.75, n.11, p.827-831, 1997. Disponível em: <http://www.ncbi.nlm.nih.gov/pubmed/944619>. Acesso em: 20 nov. 2011

KIRKBRIDE, C.A. Diagnoses in 1,784 ovine abortions and stillbirths. Journal Veterinary Diagnostic Investigation, v.5, p.398-402, 1993. Disponível em: <http://vdi.sagepub.com/ content/5/3/398.full.pdf $>$. Acesso em: 20 nov. 2011. doi: $10.1177 / 104063879300500316$.

LANDER, K.P. The development of a transport and enrichment medium for Campylobacter fetus. British Veterinary Journal, v.146, p.327-333, 1990. Disponível em: <http:// www.cabdirect.org/abstracts/19902209833.html>. Acesso em: 12 dez. 2010.

LOBO, R.N.B. Melhoramento genético de caprinos e ovinos: desafios para o mercado. Sobral: Embrapa Caprinos, 2002. 36p. (Embrapa Caprinos. Documentos, 39).

NÓBREGA, J.E. et al. Mortalidade perinatal de cordeiros no semi-árido da Paraíba. Pesquisa Veterinária Brasileira, v.25, n.3, p.171-178, 2005. Disponível em: <http:// www.pvb.com.br $/$ ?link $=$ verart\&tipo $=I D \&$ campo $1=65>$. Acesso em: 12 dez. 2010

PINHEIRO, J.W. et al. Prevalence and risk factors associated to infection by Toxoplasma gondii in ovine in the State of Alagoas, Brazil. Parasitology Research, v.105, p.709-715, 2009. Disponível em: <http://www.springerlink.com/content/ ag2577420406152w/>. Acesso em: 20 nov. 2011. doi:. 10.1007/ s00436-009-1472-3. 
QUINN, P.J. et al. Microbiologia veterinária e doenças infecciosas. In:____. Corynebacterium species and Rhodococcus equi. 2.ed. Porto Alegre: Artmed, 2005. Cap.10, p. 137-143.

MORAES E.P. et al. Toxoplasma gondii diagnosis in ovine aborted fetuses and stillborns in the State of Pernambuco, Brazil. Veterinary Parasitology, v.183, n.1-2, p.152-155, 2011. Disponível em: <http://www.sciencedirect.com/science/article/ pii/S0304401711004651>. Acesso em: 20 nov. 2011. doi:. 10.1016/j.vetpar.2011.06.023.

SAMBROOK, J.; RUSSELL, D.W. Molecular cloning a laboratory manual. 3.ed. New York: Cold Spring Harbor Laboratory, 2001. p.2344.

VARGAS, A.C. et al. Isolamento de Campylobacter jejuni em feto ovino abortado: relato de caso. Arquivo Brasileiro de Medicina Veterinária e Zootecnia, v.57, n.3, p.317-320,
2005. Disponível em: <http://www.scielo.br/ scielo.php?pid $=$ S 0 102-093500007\&script $=$ sci_arttext $>$. Acesso em: 20 nov. 2011. doi: 10.1590/S010209352005000300007 .

WAGENAAR, J.A. et al. Comparative study using ampli?ed fragment length polymorphism fingerprinting, PCR genotyping, and phenotyping to differentiate Campylobacter fetus strains isolated from animals. Journal of Clinical Microbiology, v.39, n.6, p.2283-2286, 2001. Disponível em: <http:// jcm.asm.org/content/39/6/2283.short>. Acesso em: 20 nov. 2011. doi: 10.1128/JCM.39.6.2283-2286.2001.

WEST, D.M. et al. A possible role for Neospora caninum in ovine abortion in New Zealand. Small Ruminant Research, v.62, p.135-138, 2006. Disponível em: <http:// www.journals.elsevierhealth.com/periodicals/rumin/article/ S09214488\%2805\%2900312-3/abstract>. Acesso em: 20 nov. 2011. doi:. 10.1016/j.smallrumres.2005.07.041. 